\title{
Rainfall-Runoff Simulation and Modelling Using HEC-HMS and HEC-RAS Models: Case Study Tabuk, Saudi Arabia
}

\author{
Ali Alsubeai, Suzette R. Burckhard \\ Department of Civil \& Environmental Engineering, South Dakota State University, Brookings, SD, USA \\ Email: alialsubaie98@gmail.com, Suzette.Burckhard@sdstate.edu
}

How to cite this paper: Alsubeai, A. and Burckhard, S.R. (2021) Rainfall-Runoff Simulation and Modelling Using HEC-HMS and HEC-RAS Models: Case Study Tabuk, Saudi Arabia. Natural Resources, 12, 321-338. https://doi.org/10.4236/nr.2021.1210022

Received: August 30, 2021

Accepted: October 18, 2021

Published: October 21, 2021

Copyright $\odot 2021$ by author(s) and Scientific Research Publishing Inc. This work is licensed under the Creative Commons Attribution International License (CC BY 4.0).

http://creativecommons.org/licenses/by/4.0/

\begin{abstract}
Flooding regimes in arid regions are heavily influenced by climate change, water shortage, water regulations, and increased water demands. The low amount of annual precipitation due to the desert climate may lead to false estimations of flooding hazards. This study analyzed flash floods caused by short-intense rainstorms. The objective of this study was to determine flood risk related to identified precipitation depths. The project quantized the runoff corresponding to different design storms and used hydraulics and geospatial data to determine flood elevations. The study constructed hydrologic and hydraulic models to quantify flood hazards in the adjacent area of Wadi Abu Nashayfah. Peak discharges for the wadi were computed by using observed rainfall data, and the output of this process was applied to compute water surface elevations within the flow channel. At upstream, there is a high potential of flooding when Wadi Abu Nashayfah receives a minimum of 25 $\mathrm{mm}$ of rain which generates $40.60 \mathrm{~m}^{3} / \mathrm{s}$ of peak discharge, thus, at this point the stream will overtop its banks and risking the adjacent area. In the second case, flow will overtop its banks when the channel receives at least $35 \mathrm{~mm}$ of rain and peak discharge level to $67.20 \mathrm{~m}^{3} / \mathrm{s}$. While flow will reach bank full point if wadi Abu Nashayfah receives $10.00 \mathrm{~mm}$ of rain and generates 14.80 $\mathrm{m}^{3} / \mathrm{s}$ of streams downstream. The depth of precipitation at which the channel was overtopped was determined in several locations. The predicted overtopping was compared to historic events with good agreement.
\end{abstract}

\section{Keywords}

Remote Sensing, Climate Variability, Watershed Modeling, Arid Region

\section{Introduction}

Urbanization in arid regions requires the design of stormwater runoff quantity 
control structures because of the high-intensity, short-duration rain spells in these regions. Such high-intense storms, combined with the poor drainage potential of desert soils, can contribute to floods, property damage and loss of life. As a result, stormwater control systems were built in the 1960 s to handle flooding in arid regions [1]. Flooding regimes in arid and semi-arid regions are heavily influenced by climate change and water shortage, water regulations, and increased water demands.

Floods are very rare and infrequent in arid regions, are hard to predict and can cause severe harm to people's lives and infrastructure as well. The low amount of annual precipitation due to the desert climate may lead to false estimations of flooding hazards. Rainfall events in arid regions are characterized as short-term high-intensity events where there is a shortage of time for water to enter soil layers, so most of water generates surface flow or runoff.

Tabuk's flash flooding is not an exception to this pattern. Rapid population development, urbanization, and the transformation of vast areas of sandy desert into concrete constructed impervious surfaces that delay rainwater runoff have significantly increased the risk of dangerous flash flooding events in Tabuk for the next 25 years due to the lack of a river and drainage outlets to the sea [2]. Hence, flash flood mitigation has now become a major challenge for Tabuk's city planners [3]. It is critical to recognize the city areas and residents that are vulnerable to flash flooding in order to prepare effective flood mitigation plans for the city [4] [5] [6]. The purpose of this study is to provide an assessment and evaluating flood hazards for Tabuk region.

However, in the arid region, the runoff generation is extremely high due to the combination between intense rainfall events and the lack of vegetation cover. Flow regime from a catchment is the result of a dynamic combination of climatologic and catchment characteristics, and this interaction affects runoff's spatial and temporal variability. Furthermore, watershed attributes such as area, catchment size, slope, channel network, soil, vegetation cover, and underlying geology are all influencing runoff generation.

Understanding the spatial and temporal variance of model inputs and controls, as well as their use in distributed modeling, improves our understanding and ability to simulate diverse hydrological processes. The remote sensing and Geographic Information System (GIS) developments are now well-established methods for producing and interpreting spatially dispersed data for use in distributed hydrological models.

\section{Study Area}

1) Geography and location

The Tabuk region is located in the extreme northwest of Saudi Arabia, with Jordan bordering on the north and the Gulf of Aqaba and the Red Sea bordering on the west (Figure 1). Surrounding it are three other administrative regions; $\mathrm{Al}$ Jouf, Hael, and Madinah. Evidently, the strategic position of the region is considered 


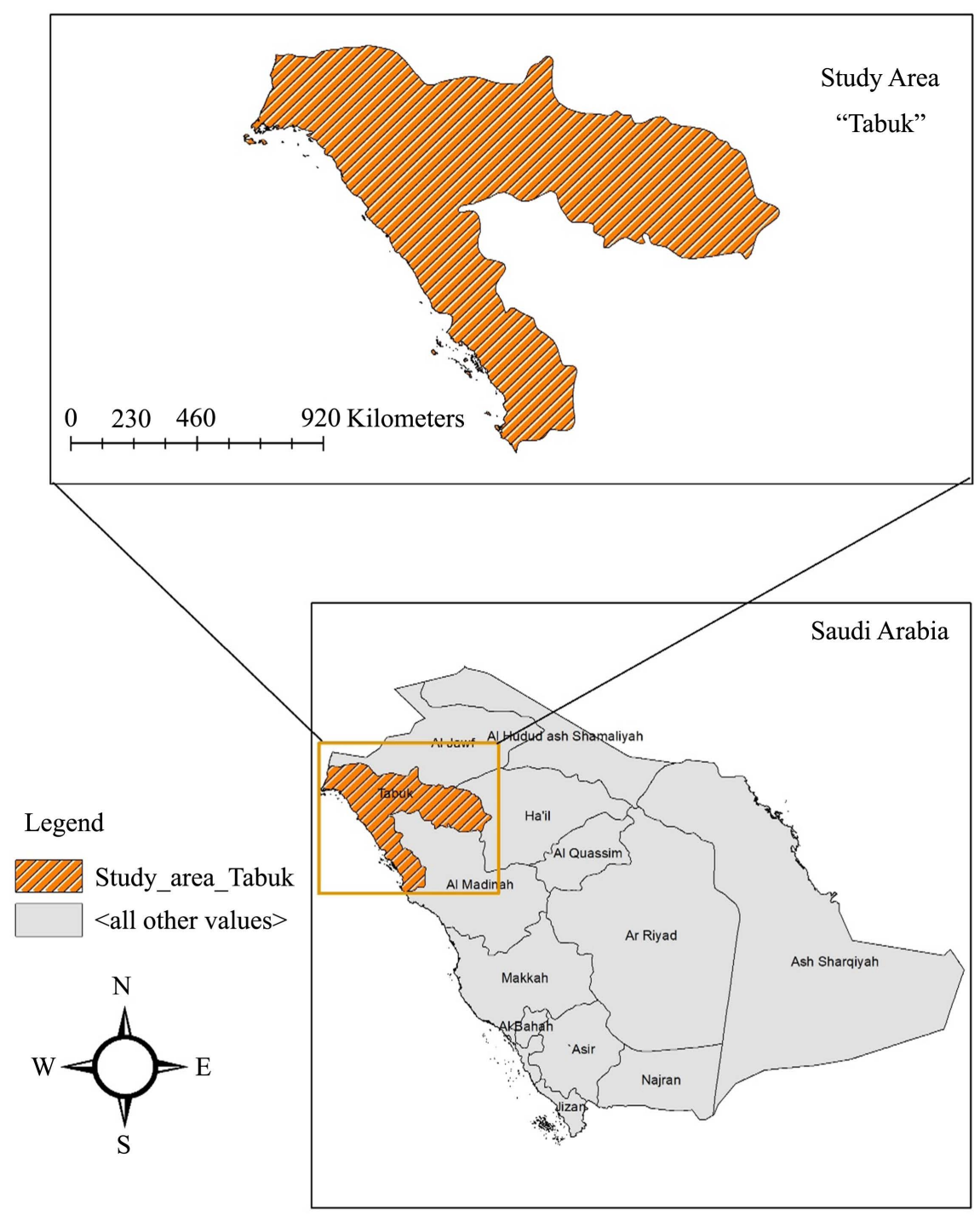

Figure 1. Tabuk geography region.

to be one of the most significant elements of economic growth due to its long seafront in the Red Sea.

2) Wadi Abu Nashayfah Morphology and hydrological processes

The downstream control point is located at Wadi Abu Nashayfah, which is the longest wadi crossing the city of Tabuk at $25 \mathrm{~km}$ long. The city of Tabuk's culverts and bridges are specifically designed to avoid ephemeral flash flood incidents. Wadi Abu Nashayfah was measured and divided into three essential sections based on cross sectional characteristics mainly the width of the channel (Wadi). The first section is $90 \mathrm{~m}$ width upstream along with the second section $130 \mathrm{~m}$ and the last section $160 \mathrm{~m}$ downstream.

In addition, being a border area allows a large proportion of trade access to Egypt, Jordan, Syria, Lebanon, and Turkey, as well as the movement of passengers and pilgrims from those countries and other countries in North Africa. The area of the Tabuk Region is 139,000 square kilometers or about $6.2 \%$ of the total 
area of the Kingdom. The Tabuk Region stretches from North to South covering over 580 kilometers and extends over 480 kilometers from East to West [7].

3) Climate and topography

In the case of both the Tabuk Region and the city of Tabuk different drivers of environmental degradation have been identified. On the one hand, unsustainable growth patterns and inadequate infrastructure are challenging future economic development and compromising existing natural resources. On the other hand, the burden on the environment is exacerbated by climate change, which is currently driving the already severe climate to more extreme conditions [7].

4) Precipitation

The dominant contribution to the low annual average rainfall in arid regions is short, high intensity rainstorms. Rainfall in the Tabuk region (Figure 2) appears to differ considerably from year to year, with an erratic distribution in time and space.

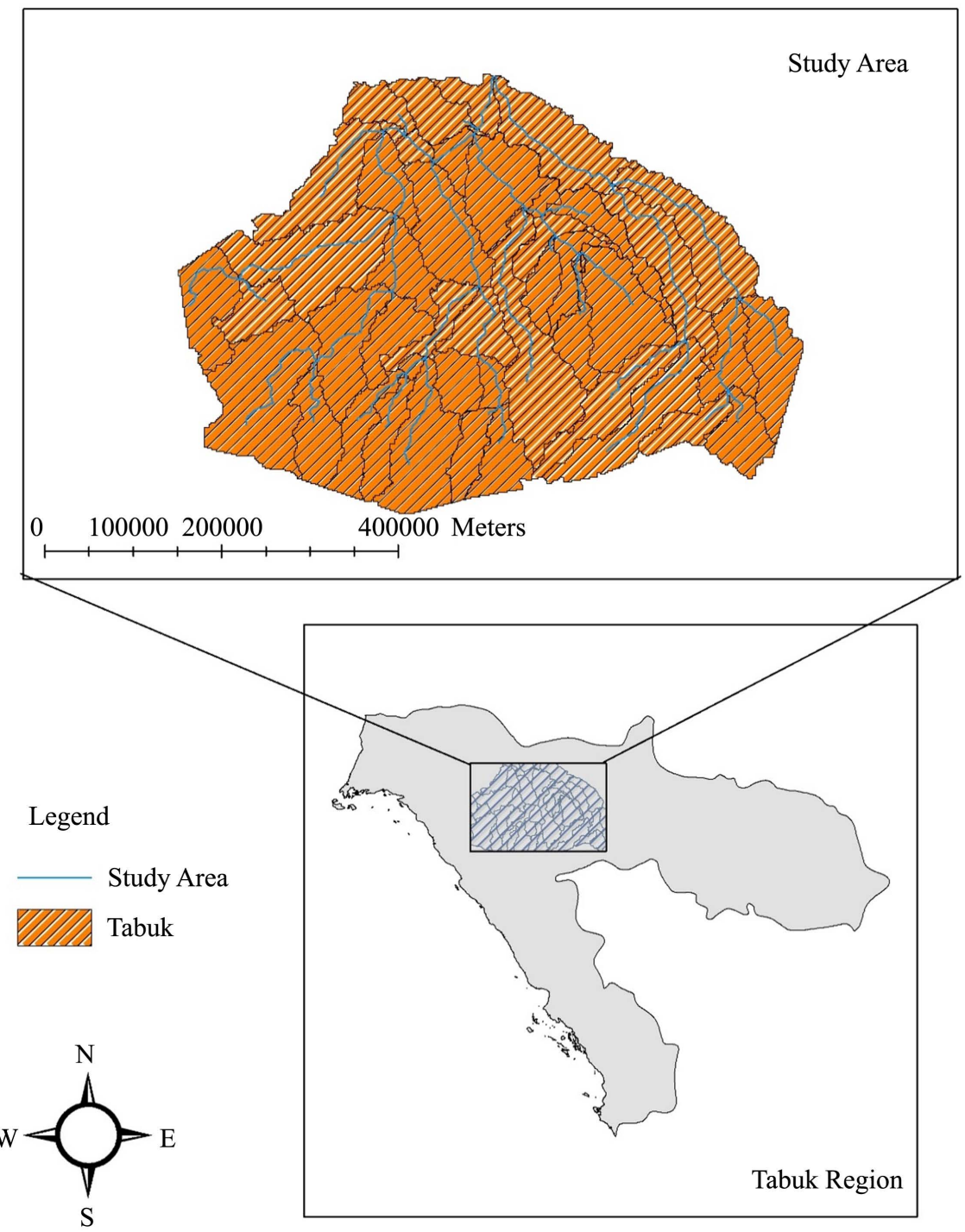

Figure 2. Tabuk watershed area and stream flows. 
As an illustrative example of the extreme yearly variability, Tabuk rain gauge measured the annual rainfall to be $6.8,13.70,21.90,13.00,39.60,51.10$, and $13.50 \mathrm{~mm}$ over seven years. On one single day, $76.60 \mathrm{~mm}$ of rainfall occurred, even though the total annual rainfall in the same year was $92.20 \mathrm{~mm}$ observed data from Tabuk rain gauge. These types of rainfall events can lead to substantial surface runoff, resulting in severe soil erosion. Weather behavior and topographical characteristics play important roles in this variation. Around $70 \%$ of the total annual rainfall occurs during November, December, January, February, and March.

\section{5) Temperature}

The entire Tabuk region investigated here currently has one climatic station. Tabuk station, which has complete climatic data, is located in Tabuk City. Tabuk climate is characterized by warm and dry summers (May to September) with mean degree $28.54^{\circ} \mathrm{C}, 32.43^{\circ} \mathrm{C}, 34.48^{\circ} \mathrm{C}, 34.67^{\circ} \mathrm{C}$, and $31.26^{\circ} \mathrm{C}$ respectively. In addition to moderate cold and wet winters (October to April) (Table 1), the average annual temperature is $23.52^{\circ} \mathrm{C}(1999-2018)$.

6) Surface runoff

Tabuk catchment is exemplified by ephemeral wadis, where a stream runs fully for a short period of time, usually during and after heavy rain events, and is dry most of the year. Flash floods events fill desert dams and may recharge groundwater resources. The complex relationship between rainfall and streamflow is influenced by many factors, such as catchment slope, land cover type and density, soil type and infiltration rate, and evapotranspiration. Moreover, the quality and quantity of streamflow are strongly affected by urbanization and agricultural activity.

\section{Methods}

\section{1) Hydrological and Hydraulic Modeling}

Defined precipitation data between the years 1978 and 2013 at daily time intervals have been gathered, including historical and real-time observations. In addition, daily data for the selected years were available. Detection and filtering of abnormal and missing data were automated using statistical routines. The data set includes annual and monthly precipitations were provided by Tabuk meteorological station. However, the application of any climate model requires a validation process to make sure that the results are in an acceptable range (Figure 3).

Table 1. Temperature description for the period of 1999-2018 (Tabuk Meteorological Station).

\begin{tabular}{ccccccc}
\hline Month & Jan & Feb & Mar & Apr & May & Jun \\
\hline Average ${ }^{\circ} \mathrm{C}$ & 10.59 & 13.40 & 17.96 & 23.66 & 28.54 & 32.43 \\
\hline Month & Jul & Aug & Sep & Oct & Nov & Dec \\
\hline Average ${ }^{\circ} \mathrm{C}$ & 34.48 & 34.67 & 31.26 & 25.64 & 17.31 & 12.25 \\
\hline
\end{tabular}




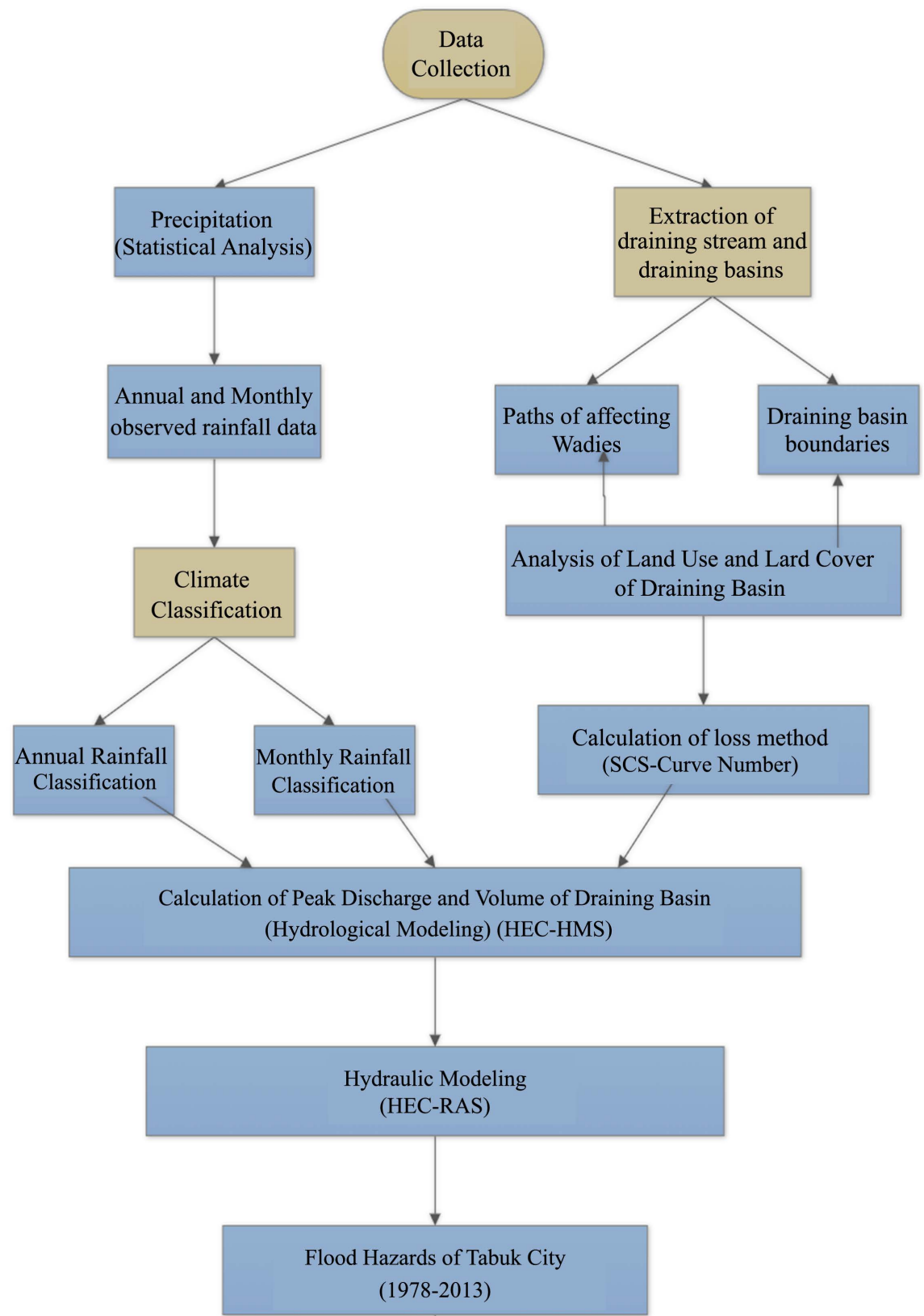

Figure 3. Flowchart showing the process applied in this study.

Fitting spatial statistical models to stream network data is challenging because it requires multidisciplinary skills in aquatic ecology, geographic information science, and spatial statistics. In addition, specialized geographic information system in ArcGIS tools is needed to generate the spatial information needed to fit spatial models to stream network data. ArcGIS different versions of geoprocessing toolboxes have been provided to help users generate these spatial data: the functional linkage of water basins and stream flows toolbox and the spatial tools for the analysis of river systems.

The watershed model created in HEC-HMS follows the form of the Sacramento District Corps office HEC-1 forecast model of the basin [8]. This model 
utilizes one sub-basin above the designated reservoir that provides runoff into the reservoir. Below the reservoir, there is a routed channel reach and another sub-basin that provides runoff downstream.

HEC-RAS is an integrated system of software, designed for interactive use in a multi-tasking, multi-user network environment. The system contains three one-dimensional hydraulic analysis components for steady flow water surface profile computations; unsteady flow simulation; and movable boundary sediment transport computations. A key element is that all three components use a common geometric data representation and common geometric and hydraulic computation routines. In addition to the three hydraulic analysis components, the system contains several hydraulic design features that can be invoked once the basic water surface profiles are computed.

The hydrologic, hydraulic, and floodplain models in this study were built using HEC-HMS and HEC-RAS. This model was created to simulate rainfallrunoff processes in a variety of watershed forms. HEC-HMS employs a few sub-models to describe various components of the runoff process, including neuromas penetration methods, unit hydrographs, and flood routing techniques [8].

The major steps followed in this study include generating a digital elevation (DEM) for the study area, delineate the watershed, use HEC-HMS to develop a hydrological model for the watershed, and use HEC-RAS model to develop one dimensional (1D) hydraulic model and generate flood risk maps for Wadi Abu Nashayfah.

2) Basin model input parameters and losses calculations

Basin characteristics such as area, $\mathrm{CN}$ number, and streams parameters were extracted from ArcGIS. Table 2 shows the input parameters for basins and streams.

There are many options available for loss calculations, including initial and constant loss rate, and SCS curve number method. In this analysis, the SCS curve number approach is used to calculate runoff losses. The rainfall excess is calculated using the SCS formula as a function of total precipitation, soil cover, land use, and antecedent moisture content.

The SCS runoff equation is as follows [9].

$$
Q=\frac{\left(P-I_{a}\right)^{2}}{\left(P-I_{a}\right)+S}
$$

where: $Q=$ direct runoff (in), $P=$ rainfall (in).

Table 2. HEC-HMS model parameters.

\begin{tabular}{ccc}
\hline Model & Method & Parameters \\
\hline Loss & SCS Curve Number & Initial abstraction (mm), CN, Imperviousness (\%) \\
Transform & SCS Unit Hydrograph & Lag time (min) \\
Routing & Muskingum & Channel length (m), Slope, Manning's n, Channel width \\
\hline
\end{tabular}


The initial abstractions $I_{a}$ is a percentage of $S$ as follows:

$$
I_{a}=0.2 S
$$

Noting that $S$ is the potential max retention which can be computed as:

$$
S=\frac{1000}{C N}-10
$$

Initial Abstraction is a parameter that accounts for all losses prior to runoff and consists mainly of interception, infiltration, evaporation, and surface depression storage. This parameter is assumed as 0.2 of potential max retention based on watersheds studied in humid regions. Accordingly, vegetation cover in humid regions is larger compared to arid regions which low the potential of intercepting flooding in arid regions. Another example, evaporation rates are higher at higher temperatures because as temperature increases. In sunny, warm weather the loss of water by evaporation is greater than in cloudy and cool weather.

The CN method involves $\mathrm{CN}$ values, initial abstraction, and impervious area details. Using the soil map, as well as the land use and land cover maps, the CN layer was generated in GIS. The soil layer has four major hydrological groups such as A, B, C, and D, which are interpreted in GIS for developing the CN layer. After developing the $\mathrm{CN}$ map in GIS, it was found that the $\mathrm{CN}$ varies at different locations from a maximum of 81 to a minimum of 58 (Table 3). The average CN for the sub-basins is 72, which represents the majority of Wadi Abu Nashayfah catchment curve number.

\begin{tabular}{|c|c|c|c|c|c|c|c|c|}
\hline \multicolumn{9}{|c|}{ Tabuk Watershed } \\
\hline Subbasin & $\begin{array}{l}\text { Area } \\
\mathrm{km}^{2}\end{array}$ & $\begin{array}{c}\text { Curve } \\
\text { Number }\end{array}$ & Subbasin & $\begin{array}{l}\text { Area } \\
\mathrm{km}^{2}\end{array}$ & $\begin{array}{c}\text { Curve } \\
\text { Number }\end{array}$ & Subbasin & $\begin{array}{l}\text { Area } \\
\mathrm{km}^{2}\end{array}$ & $\begin{array}{c}\text { Curve } \\
\text { Number }\end{array}$ \\
\hline 470 & 3.98 & 77 & 630 & 19.11 & 73 & 780 & 9.92 & 77 \\
\hline 480 & 4.28 & 74 & 640 & 6.6 & 78 & 790 & 9.98 & 70 \\
\hline 490 & 5.72 & 80 & 650 & 3.87 & 73 & 800 & 13.1 & 71 \\
\hline 500 & 5.51 & 80 & 660 & 12.73 & 73 & 810 & 21.36 & 66 \\
\hline 510 & 14.72 & 81 & 670 & 3.99 & 75 & 820 & 4.85 & 69 \\
\hline 520 & 11.58 & 78 & 680 & 4.34 & 79 & 830 & 23.37 & 71 \\
\hline 530 & 6.68 & 81 & 690 & 13.68 & 76 & 840 & 7.98 & 70 \\
\hline 540 & 2.93 & 75 & 700 & 4.91 & 75 & 850 & 13.97 & 58 \\
\hline 550 & 11.73 & 75 & 710 & 9.44 & 75 & 860 & 7.7 & 58 \\
\hline 560 & 17.41 & 80 & 720 & 5.68 & 66 & 870 & 6.02 & 58 \\
\hline 570 & 12.38 & 76 & 730 & 4.7 & 70 & 880 & 5.98 & 58 \\
\hline 580 & 13.91 & 72 & 740 & 6.42 & 71 & 890 & 4.87 & 72 \\
\hline 590 & 14.52 & 72 & 750 & 11.43 & 65 & 900 & 6.59 & 72 \\
\hline 600 & 6.25 & 75 & 760 & 6.29 & 70 & 910 & 4.52 & 59 \\
\hline 610 & 11.72 & 71 & 770 & 6.68 & 79 & 920 & 6.1 & 59 \\
\hline 620 & 19.17 & 71 & & & & & & \\
\hline
\end{tabular}

Table 3. Curve number calculated for subbasins in study area. 


\section{Results and Discussion}

This study analyzed flash floods caused by short-intense rainstorms. The project quantized the runoff corresponding to different design storms and used hydraulics and geospatial data to determine flood elevations. Table 4 presents the runoff volumes and peak discharge at the outlet of Wadi Abu Nashayfah watershed. Figure 4 shows the relationship between precipitation and peak discharge for the watershed. This trend shows increasing in peak discharge and

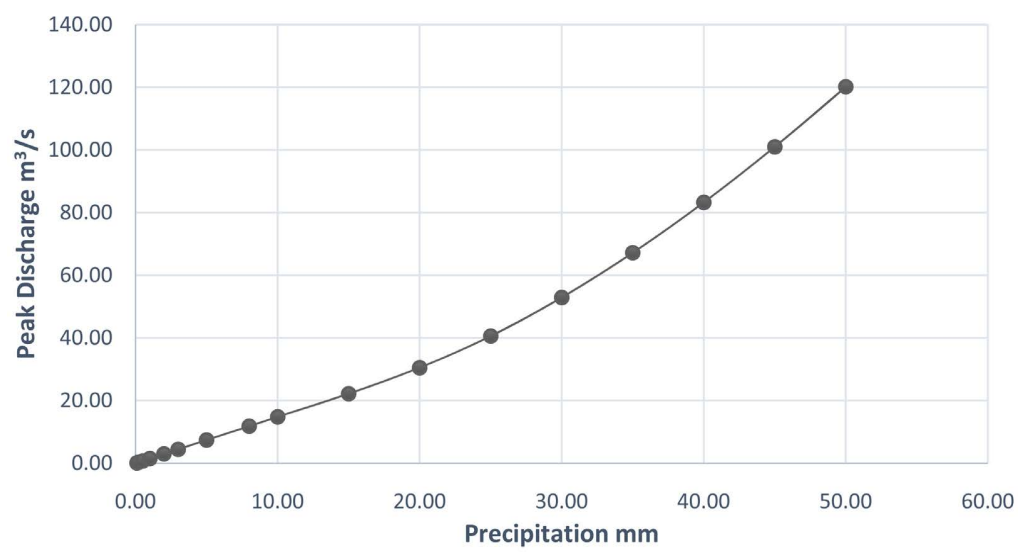

Figure 4. Peak discharge interacting with precipitation over Wadi Abu Nashayfah.

Table 4. Runoff volumes and peak discharges at the outlet for Tabuk watershed.

\begin{tabular}{cccc}
\hline $\mathrm{N}$ & $\begin{array}{c}\text { Precipitation } \\
(\mathrm{mm})\end{array}$ & $\begin{array}{c}\text { Runoff Volume } \\
\left(\times 1000 \mathrm{~m}^{3}\right)\end{array}$ & $\begin{array}{c}\text { Peak Discharge } \\
\left(\mathrm{m}^{3} / \mathrm{s}\right)\end{array}$ \\
\hline 1 & 0.10 & 0.02 & 0.10 \\
2 & 0.20 & 0.03 & 0.30 \\
3 & 0.50 & 0.08 & 0.70 \\
4 & 1.00 & 0.17 & 1.50 \\
5 & 2.00 & 0.34 & 3.00 \\
6 & 3.00 & 0.51 & 4.40 \\
7 & 5.00 & 0.85 & 7.40 \\
8 & 8.00 & 1.36 & 11.80 \\
9 & 10.00 & 1.69 & 14.80 \\
10 & 15.00 & 2.55 & 22.20 \\
11 & 20.00 & 3.50 & 30.50 \\
12 & 25.00 & 4.67 & 40.60 \\
13 & 30.00 & 6.08 & 52.90 \\
14 & 35.00 & 7.72 & 67.20 \\
15 & 40.00 & 9.57 & 83.30 \\
16 & 45.00 & 11.60 & 101.00 \\
\hline 50.00 & 13.81 & 120.20 \\
\hline & & &
\end{tabular}


runoff volume following the raising of precipitation depth which reflects the natural relationship between rainfall and runoff. Precipitation values ranged between 0 to $50 \mathrm{~mm}$ which is the dominating case in arid region and certainly Wadi Abu Nashayfah. While peak discharge and runoff volume ranged in 0.10 $120 \mathrm{~m}^{3} / \mathrm{s}$ and $0.02-13.8 \mathrm{~m}^{3}$ respectively.

HEC-RAS was run to compute water surface elevation corresponding to the peak discharge computed by HEC-HMS at the defined cross sections. There are three types of cross sections applied in this $1 \mathrm{D}$ simulation. As a matter of fact, channel cross sections have several dimensional measurements which can be categorized into three main shapes. Accordingly, W 90, W 130, and W 160 are sorted based on variations on channel width (Table 5).

Peak discharges for Wadi Abu Nashayfah were computed by using observed precipitation data from Tabuk metrological station, the output of this process was applied to compute water surface elevation. At upstream, there is a high potential of flooding when Wadi Abu Nashayfah receives a minimum of $25 \mathrm{~mm}$ of rain which generates $40.60 \mathrm{~m}^{3} / \mathrm{s}$ of peak discharge, thus, at this point the stream will overtop its banks and risking the adjacent area. In the second case, flow will

Table 5. Precipitation, peak discharge, and water surface elevation for Wadi Abu Nashayfah catchment.

\begin{tabular}{|c|c|c|c|c|c|}
\hline \multicolumn{6}{|c|}{ Tabuk Watershed } \\
\hline $\mathrm{N}$ & $\begin{array}{l}\text { Precipitation } \\
\mathrm{mm}\end{array}$ & $\begin{array}{c}\text { Peak Dis } \\
\mathrm{m}^{3} / \mathrm{s}\end{array}$ & $\begin{array}{l}\text { WS Elevation } \\
\text { (Section } 1)\end{array}$ & $\begin{array}{l}\text { WS Elevation } \\
\text { (Section 2) }\end{array}$ & $\begin{array}{c}\text { WS Elevation } \\
\text { (Section 3) }\end{array}$ \\
\hline 1 & 0.10 & 0.10 & 792.18 & 755.14 & 735.14 \\
\hline 2 & 0.20 & 0.30 & 792.30 & 755.22 & 735.23 \\
\hline 3 & 0.50 & 0.70 & 792.45 & 755.33 & 735.34 \\
\hline 4 & 1.00 & 1.50 & 792.64 & 755.47 & 735.48 \\
\hline 5 & 2.00 & 3.00 & 792.89 & 755.65 & 735.66 \\
\hline 6 & 3.00 & 4.40 & 793.06 & 755.78 & 735.79 \\
\hline 7 & 5.00 & 7.40 & 793.35 & 755.99 & 736.01 \\
\hline 8 & 8.00 & 11.80 & 793.68 & 756.24 & 736.25 \\
\hline 9 & 10.00 & 14.80 & 793.87 & 756.37 & 736.39 \\
\hline 10 & 15.00 & 22.20 & 794.26 & 756.66 & \\
\hline 11 & 20.00 & 30.50 & 794.63 & 756.93 & \\
\hline 12 & 25.00 & 40.60 & 795.01 & 757.21 & \\
\hline 13 & 30.00 & 52.90 & & 757.50 & \\
\hline 14 & 35.00 & 67.20 & & 757.80 & \\
\hline 15 & 40.00 & 83.30 & & & \\
\hline 16 & 45.00 & 101.00 & & & \\
\hline 17 & 50.00 & 120.20 & & & \\
\hline
\end{tabular}

*Bold values are bank full elevations. 
overtop its banks when the channel receives at least $35 \mathrm{~mm}$ of rain and peak discharge level to $67.20 \mathrm{~m}^{3} / \mathrm{s}$. While flow will reach bank full point if wadi Abu Nashayfah receives $10.00 \mathrm{~mm}$ of rain and generates $14.80 \mathrm{~m}^{3} / \mathrm{s}$ of streams at downstream. The high flow depth is within this channel is essentially based on the topography of the channel and location of Tabuk city which is located at low elevation.

Table 5 summarizes HEC-RAS and HEC-HMS results corresponding to precipitation data. Again, water surface elevation ranges between $735-795 \mathrm{~m}$ in different sections of Wadi Abu Nashayfah (Table 5). Elevation levels were obtained from 10 meter-DEM. Streamflow direction downhill from upstream where mountains are dominating, flowing along to downstream which is located at lower elevation.

To develop the flood hazard map, the peak flows for each sub-catchment simulated by HEC-HMS were inputted into HEC-RAS and the solution generated by HEC-RAS model was imported and read by Geographic Information System (GIS). The process was repeated for different cross section shapes. Each time, a new scatter point file containing the water depths resulting from the HEC-RAS simulation was read into GIS as two-dimensional scatter points that are connected to delineate the flood inundation.

By analyzing the flooding and the water surface elevation for the different hydraulic modelling results (Table 5), some selection criteria can be set up for determining the type of DEM to be used. The 10-meter DEM has a low resolution; however, the effectiveness of its use in hydraulic modelling has been illustrated for the Tabuk study. The model improves as precipitation depth and peak discharge data are added, making it more expensive but also introducing the variation between cross-sections.

Modeling first section shows that the results (water surface elevation) are affected by cross section variations. Water surface elevations were obtained from DEM, and they vary from 792.18 to $796.84 \mathrm{~m}$. While peak discharge has a range of $0.10-120.20$. The result of this simulation indicates that the channel bank is full when watershed receives $25 \mathrm{~mm}$ or above and peak discharge is $40.60 \mathrm{~m}^{3} / \mathrm{s}$. At this point the channel reaches its maximum capacity and the stream overtop to reach the adjacent area.

Similarly, modeling second section shows that the results (water surface elevation) are affected by cross sections variations. Water surface elevations were obtained from DEM, and they vary from 755.14 to $758.65 \mathrm{~m}$. While peak discharge has a range of $0.10-120.20$. The result of this simulation indicates that the channel bank is full when watershed receives $35 \mathrm{~mm}$ or above and peak discharge is $67.20 \mathrm{~m}^{3} / \mathrm{s}$. At this point, the channel reaches its maximum capacity and the stream overtop reaches the adjacent area.

Modeling third section shows that the results (water surface elevation) are affected by cross sections variations. Water surface elevations were obtained from DEM, and they vary from 735.14 to $738.67 \mathrm{~m}$. While peak discharge has a range of $0.10-120.20$. The result of this simulation indicates that the channel bank is 
full when watershed receives $10 \mathrm{~mm}$ or above and peak discharge is $14.80 \mathrm{~m}^{3} / \mathrm{s}$. At this point the channel reaches its maximum capacity and the stream overtop to reach the adjacent area.

Wadi Abu Nashayfah watershed was delineated form DEM by using ArcGIS. The delineated DEM was exported HEC-HMS to calculating peak discharges at different points on the watershed. HEC-RAS was mainly used for simulation stream data to locate at which point the channel exceeds its capacity and their high potential of flooding occurrence.

This influence increases as precipitation data and peak discharges are incorporated into the model and lead to greater water level variations. The variation in cross sections based on width, depth and length of channel produce larger variability but they are maintained when DEM data are added. For each precipitation depth, the smaller variations are for the lowest discharges. In general, it can be noted that for any discharge, the more detailed the water surface model represented, the greater sensitivity of the hydraulic results to roughness coefficient variations. The analysis of the water surface model at 10-meter DEM resolution shows variations between three sections, indicating little significant difference between them.

First and second sections were affected by channel width showing increasing in water surface elevation along with precipitation death and peak discharge. On the other hand, third section simulation presents decreasing in water surface elevation while the channel is characterized with $160 \mathrm{~m}$ width which is the maximum width for Wadi Abu Nashayfah basin. This downstream section has the maximum possibility of flooding when it receives only $10 \mathrm{~mm}$ of rain. The adjacent area of this downstream section is mainly characterized as open spaces where there are significant dangers of occurring flash flooding to the transportation system, agriculture lands, and wildlife.

Third section has the least elevation when channel bank is full after receiving $10 \mathrm{~mm}$ of precipitation. At this point, streamflow overtops the channel edges to the adjacent area which is mostly urban area including residential houses, roads, and properties. Tabuk has suffered from high intense storm events in last decades. Those events are the primary cause of generating severe floods.

Storms of high intensity and varying durations occur from time to time. However, the probability of these heavy rainfalls varies with locality. The first step in designing engineering projects dealing with flood control, and gully control are to determine the probability of occurrence of a particular extreme rainfall. This information is determined by the frequency analysis of point rainfall data.

Weibull formula is the most commonly used plotting position formula. Having calculated $\mathrm{P}$ and $\mathrm{T}$ for all the events in the series, the variation of rainfall magnitude is plotted against the corresponding $\mathrm{T}$ on semi-log or log-log paper. The rainfall magnitude for any recurrence interval can be determined by extrapolating the plot between magnitude and recurrence interval. Empirical procedures can give good results for small extrapolations, but the errors increased with the amount of extrapolation. For more accurate results, analytical methods 
using frequency factors are used.

However, the 36 annual total rainfall depths were subsequently ranked from high to low and the corresponding probabilities of exceedance were estimated with Weibull method (Table 6) [10].

Table 6. Probabilities of recurrence flooding events exceeded $10 \mathrm{~mm}$ estimated with Weibull method.

\begin{tabular}{|c|c|c|}
\hline Rank & Max Rainfall (mm) & Weibull Prob \% \\
\hline 1.00 & 48.30 & 2.70 \\
\hline 2.00 & 38.80 & 5.41 \\
\hline 3.00 & 38.00 & 8.11 \\
\hline 4.00 & 36.00 & 10.81 \\
\hline 5.00 & 34.50 & 13.51 \\
\hline 6.00 & 26.10 & 16.22 \\
\hline 7.00 & 23.70 & 18.92 \\
\hline 8.00 & 22.20 & 21.62 \\
\hline 9.00 & 18.10 & 24.32 \\
\hline 10.00 & 18.00 & 27.03 \\
\hline 11.00 & 17.10 & 29.73 \\
\hline 12.00 & 12.80 & 32.43 \\
\hline 13.00 & 12.60 & 35.14 \\
\hline 14.00 & 12.40 & 37.84 \\
\hline 15.00 & 12.20 & 40.54 \\
\hline 16.00 & 11.40 & 43.24 \\
\hline 17.00 & 11.00 & 45.95 \\
\hline 18.00 & 10.30 & 48.65 \\
\hline 19.00 & 9.80 & 51.35 \\
\hline 20.00 & 9.50 & 54.05 \\
\hline 21.00 & 9.00 & 56.76 \\
\hline 22.00 & 8.00 & 59.46 \\
\hline 23.00 & 7.70 & 62.16 \\
\hline 24.00 & 7.40 & 64.86 \\
\hline 25.00 & 6.50 & 67.57 \\
\hline 26.00 & 5.80 & 70.27 \\
\hline 27.00 & 4.90 & 72.97 \\
\hline 28.00 & 4.50 & 75.68 \\
\hline 29.00 & 4.10 & 78.38 \\
\hline 30.00 & 3.30 & 81.08 \\
\hline 31.00 & 3.20 & 83.78 \\
\hline 32.00 & 2.50 & 86.49 \\
\hline 33.00 & 2.50 & 89.19 \\
\hline 34.00 & 2.00 & 91.89 \\
\hline 35.00 & 1.20 & 94.59 \\
\hline 36.00 & 1.10 & 97.30 \\
\hline
\end{tabular}


It can be noted that all of the relationships give similar values near the center of the distribution but may vary somewhat in the tails. The probability of events that exceeded $10 \mathrm{~mm}$ is $50 \%$ which means that half of rainfall events in Tabuk may cause flooding over the wadi channel (Figure 5).

This plot (Figure 5) is showing that half of rainfall events' probability occurring is above $10 \mathrm{~mm}$ with high risk of generating floods. The section 3 which has the lowest capacity and high potential of flooding would reach its maximum when the rainfall depth is $10 \mathrm{~mm}$ which represents $50 \%$ of all events in 35 -year period.

Table 7 and Table 8 summarize precipitation events that are above $10 \mathrm{~mm}$ in last three decades (1978-2013). Those precipitation events were the main cause of flooding. Tabuk climate classification divides climates into three main climate groups, with each group being divided based on annual precipitation. The three main groups are wet, average, and dry [11].

Table 7. History of precipitation events above $10 \mathrm{~mm}$ in 35 years corresponding with peak discharge and climate classification.

\begin{tabular}{|c|c|c|c|c|}
\hline $\mathrm{N}$ & Date & Precipitation $\mathrm{mm}$ & Peak Dis $\mathrm{m}^{3} / \mathrm{s}$ & Climate Classification \\
\hline 1 & 02/08/1979 & 12.2 & 16.4 & Wet \\
\hline 2 & $05 / 04 / 1979$ & 12.6 & 16.6 & Wet \\
\hline 3 & $04 / 26 / 1982$ & 23.7 & 35.0 & Wet \\
\hline 4 & $05 / 09 / 1982$ & 16.0 & 24.0 & Wet \\
\hline 5 & $11 / 09 / 1982$ & 15.3 & 22.5 & Wet \\
\hline 6 & $10 / 31 / 1984$ & 12.4 & 16.5 & Average \\
\hline 7 & $12 / 17 / 1985$ & 11.0 & 15.3 & Wet \\
\hline 8 & $12 / 18 / 1985$ & 48.3 & 145.0 & Wet \\
\hline 9 & $04 / 25 / 1986$ & 12.4 & 16.5 & Wet \\
\hline 10 & $11 / 28 / 1986$ & 12.8 & 17.0 & Wet \\
\hline 11 & $10 / 17 / 1987$ & 26.1 & 43.6 & Wet \\
\hline 12 & $10 / 16 / 1988$ & 34.5 & 65.2 & Wet \\
\hline 13 & $10 / 17 / 1988$ & 18.2 & 28.2 & Wet \\
\hline 14 & $12 / 24 / 1988$ & 12.7 & 16.8 & Wet \\
\hline 15 & $11 / 05 / 1989$ & 15.0 & 22.2 & Wet \\
\hline 16 & $12 / 26 / 1989$ & 18.1 & 28.0 & Wet \\
\hline 17 & $01 / 01 / 1991$ & 36.0 & 70.0 & Wet \\
\hline 18 & 03/22/1991 & 16.6 & 25.2 & Wet \\
\hline 19 & $05 / 10 / 2009$ & 22.2 & 33.2 & Average \\
\hline 20 & $01 / 18 / 2010$ & 38.8 & 80.3 & Wet \\
\hline 21 & $01 / 27 / 2013$ & 38.0 & 79.2 & Wet \\
\hline 22 & $01 / 28 / 2013$ & 26.0 & 42.0 & Wet \\
\hline
\end{tabular}




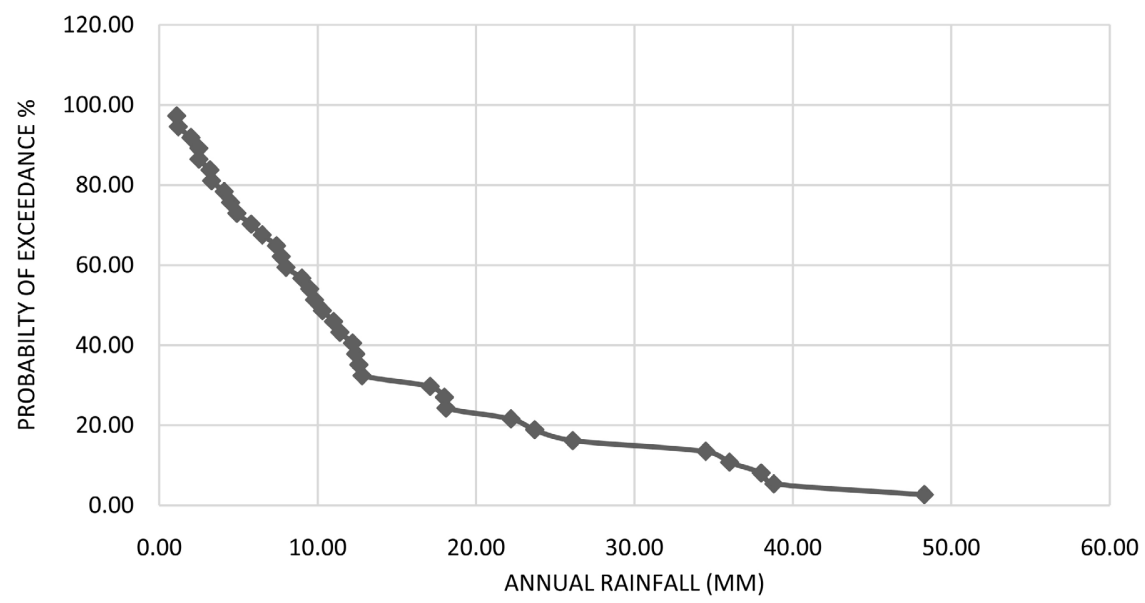

Figure 5. Probability plot of the total annual rainfall for Wadi by using linear scales for both axes.

Table 8. Number of events above $10 \mathrm{~mm}$ correlating with climate classification (1978-2013).

\begin{tabular}{|c|c|c|c|c|c|}
\hline Year & $\begin{array}{c}\text { \#Of events } \\
\text { above } 10 \mathrm{~mm}\end{array}$ & $\begin{array}{c}\text { Climate } \\
\text { Classification }\end{array}$ & Year & $\begin{array}{c}\text { \#Of events } \\
\text { above } 10 \mathrm{~mm}\end{array}$ & $\begin{array}{c}\text { Climate } \\
\text { Classification }\end{array}$ \\
\hline 1978 & 0 & Dry & 1996 & 0 & Average \\
\hline 1979 & 2 & Wet & 1997 & 0 & Average \\
\hline 1980 & 0 & Average & 1998 & 0 & Dry \\
\hline 1981 & 0 & Dry & 1999 & 0 & Average \\
\hline 1982 & 3 & Wet & 2000 & 0 & Average \\
\hline 1983 & 0 & Dry & 2001 & 0 & Average \\
\hline 1984 & 1 & Average & 2002 & 0 & Average \\
\hline 1985 & 2 & Wet & 2003 & 0 & Dry \\
\hline 1986 & 2 & Wet & 2004 & 0 & Dry \\
\hline 1987 & 1 & Wet & 2005 & 0 & Average \\
\hline 1988 & 3 & Wet & 2006 & 0 & Average \\
\hline 1989 & 2 & Wet & 2007 & 0 & Average \\
\hline 1990 & 0 & Dry & 2008 & 0 & Dry \\
\hline 1991 & 2 & Wet & 2009 & 1 & Average \\
\hline 1992 & 0 & Average & 2010 & 1 & Wet \\
\hline 1993 & 0 & Average & 2011 & 0 & Dry \\
\hline 1994 & 0 & Wet & 2012 & 0 & Average \\
\hline 1995 & 0 & Dry & 2013 & 2 & Wet \\
\hline
\end{tabular}

Most precipitation events that cause flooding were occurred in this period (1979-1991). This period was dominated by wet climate which represents the natural correlation between rainfall and runoff. In other words, high intense rainstorms during wet years are likely to generate severe flooding which can lead 
to danger the around area of Wadi Abu Nashayfah.

Most floods events occur in years classified as wet years. There is a correlation between wet years and flooding. In Tabuk, flooding events occurred in (1979, 1982, 1985, 1986, 1987, 1988, 1989, 1991, 2010 and 2013). These years are representing wet years in 35-year data set with exception to 1994 when there was no flooding event in that particular year. The maximum occurring of flooding events was in 1982 and 1988 with 3 events recorded. While 1984 and 2009 were classified as average years, there was single event recorded in each year. Dry years are insignificant in case of analyzing flooding in this watershed due to there is no event occurring in those years.

However, the first and second WS cross sections are located in high residential area (Figure 6) [12]. Streamflow in this channel has been intercepted by some built-up areas. These areas need to be removed due to the high potential of flooding and prevent properties from washing away.

This critical area is highly affected by different intense rainstorms in the past. For instance, Wadi Abu Nashayfah received $38.8 \mathrm{~mm}$ /day in Jan 18, 2010. This amount of rain exceeded water surface elevation for the wadi which allow water to overtop its banks. This extreme event has generated sever flood which harm the adjacent area. Such event caused economic loss, property damages because the adjacent area of Wadi Abu Nashayfah is mostly residentials. Flash floods created damages to properties such as, homes, businesses, vehicles, belongings, equipment. This kind of tragedy can be occurring in a short time right after rain occurring.

A major key to protecting properties is to maintain, stabilize, and expanding channel capacity in most critical spots. This wadi edge is the bulwark that stands in the soil and prevents properties from washing away and can be supported by some constructed walls. It is an essential part of the whole channel ecosystem.

Bank degradation leads to property damage or loss, sedimentation of in-stream structures, water quality deterioration, aquatic habitat damage, channel widening, and more. In Tabuk, floods are infrequent but severely damaged when they

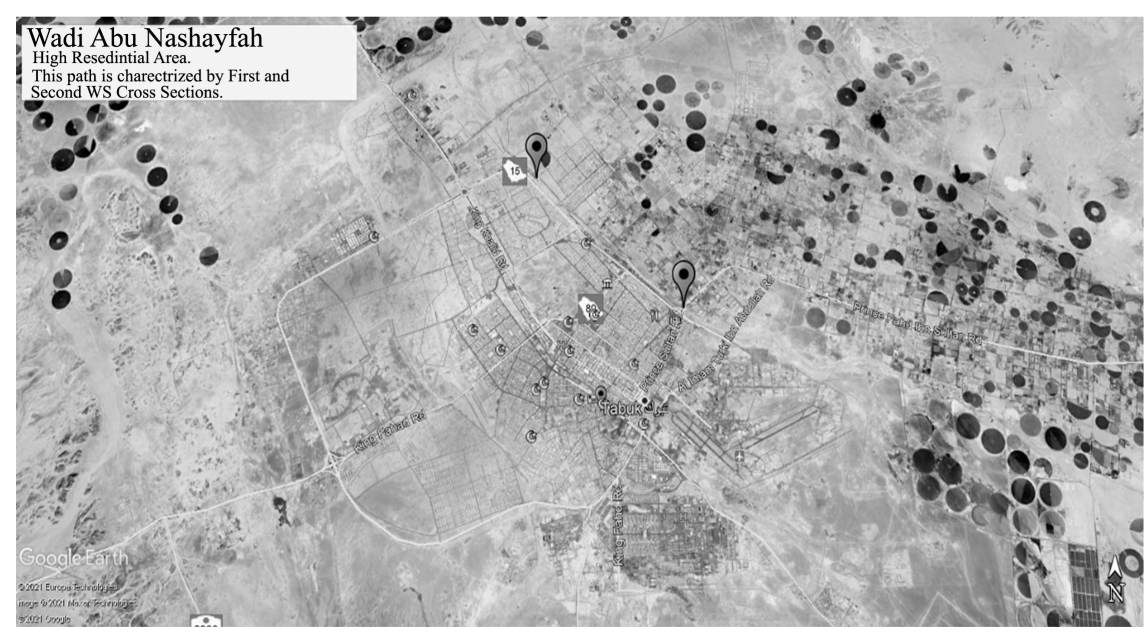

Figure 6. A path of Wadi Abu Nashayfah crossing Tabuk City [12]. 
occur. It is understood that current built-up stock of flood-prone areas must be protected against flood disasters. A rigorous flood disaster prevention strategy will include steps such as limiting additional construction or operations in the flood plain, removing some physical infrastructure from the floodway, and regulating land use patterns within the basin.

Furthermore, a comprehensive catchment planning strategy for flood adaptation is needed. The basin must be used as the primary planning unit for reducing flood damages. To that end, constructive collaboration between local/regional governments and water agencies is a top priority. This collaboration must be made possible by establishing a regulatory system that incorporates natural hazards into the spatial planning process. The key consequences of the presented strategy can be divided into two categories. The first category makes ex-ante flood risk mapping as a result of urban growth easier. Another factor, Changes in the occurrence and severity of extreme flooding, for example, may also be implemented. Second, it will aid in the practical evaluation of urban development activities that are synergized with spatial and technological flood control strategies.

\section{Conclusions}

The Tabuk area has the unique spatial location of being at the north gate of Saudi Arabia. Several geographic factors have played a major role in forming the environmental ensemble of the Tabuk area. By using multiple geographic techniques in describing, analyzing, and interpreting the data, this study significantly reveals that intense rainstorms causing flash floods have been occurring there. These rainstorms have been caused by several processes; each process has received considerable attention in this research.

This Study constructed hydrologic and hydraulic models to quantify flood hazards in the city of Tabuk. The catchment was divided into sub-catchment in the urban portion of the catchment. The hydrologic/hydraulic model simulations quantified the runoff corresponding to different storms and helped delineate the resulting flood inundation maps. Peak discharges for Wadi Abu Nashayfah were computed by using observed precipitation data from Tabuk metrological station, the output of this process was applied to compute water surface elevation. At upstream, there is a high potential of flooding when Wadi Abu Nashayfah receives a minimum of $25 \mathrm{~mm}$ of rain which generates $40.60 \mathrm{~m}^{3} / \mathrm{s}$ of peak discharge, thus, at this point, the stream will overtop its banks and risking the adjacent area. In the second case, flow will overtop its banks when the channel receives at least $35 \mathrm{~mm}$ of rain and peak discharge level to $67.20 \mathrm{~m}^{3} / \mathrm{s}$. While flow will reach bank full point if wadi Abu Nashayfah receives $10.00 \mathrm{~mm}$ of rain and generates $14.80 \mathrm{~m}^{3} / \mathrm{s}$ of streams downstream. The high flow depth is within this channel is essentially based on the topography of the channel and location of Tabuk city which is located at low elevation.

The results of this study can be utilized for planning purposes and in the design of the flood control project as it has quantized the runoff corresponding to 
different design storms and used hydraulics and geospatial data in delineating the flood zones.

\section{Conflicts of Interest}

The authors declare no conflicts of interest regarding the publication of this paper.

\section{References}

[1] Baxter, E.H., Mulamoottil, G. and Gregor, D. (1985) A Study of Residential Stormwater Impoundments: Perceptions and Policy. Water Resources Bulletin, 21, 83-88. https://doi.org/10.1111/j.1752-1688.1985.tb05354.x

[2] Sharif, H.O., Al-Juaidi, F.H., Al-Othman, A., Al-Dousary, I., Fadda, E., Uddeen, S.J. and Elhassan, A. (2014) Flood Hazards in an Urbanizing Watershed in Riyadh, Saudi Arabia. Geomatics, Natural Hazards and Risk, 7, 702-720. https://doi.org/10.1080/19475705.2014.945101

[3] Nahiduzzaman, K.M., Aldosary, A.S. and Rahman, M.T. (2015) Flood Induced Vulnerability in Strategic Plan Making Process of Riyadh City. Habitat International, 49, 375-385. https://doi.org/10.1016/j.habitatint.2015.05.034

[4] Ewea, H. (2010) Hydrological Analysis of Flooding Wastewater Lake in Jeddah, Saudi Arabia. Journal of King Abdulaziz University, 21, 125-144. https://doi.org/10.4197/met.21-1.9

[5] Alamri, Y.A. (2011) Rains and floods in Saudi Arabia. Saudi Medical Journal, 32, 311-313.

[6] Saud, M.A. (2012) Use of Remote Sensing and Gis to Analyze Drainage System in Flood Occurrence, Jeddah-Western Saudi Coast. In: Javaid, M., Ed., Drainage Systems, InTech, Rijeka, 139-164.

[7] UN-Habitat (2019) Tabuk City Profile: UN-Habitat. https://unhabitat.org/tabuk-city-profile

[8] USACE (United States Army Corps of Engineers) (2010) Hydrologic Modeling System HEC-HMS, Technical Reference Manual. USACE Hydrologic Engineering Center, Davis, CA, USA.

[9] Rallison, R.E. (1980) Origin and Evolution of the SCS Runoff Equation. Proceeding of the Symposium on Watershed Management.

[10] Weibull, W. (1939) A Statistical Study of the Strength of Material. Generalstabens Litografiska Anstalts Förlag, Stockholm.

[11] Alsubeai, A. and Burckhard, S.R. (2021) Interannual Climate Variability in Tabuk, Saudi Arabia: Impacts on Annual and Seasonal Precipitation. Atmospheric and Climate Sciences, 11, 645-657. https://doi.org/10.4236/acs.2021.114038

[12] Google Maps (2017) ARU: Tabuk Region, 1:1.500. Google Maps [online]. 